\title{
Research on the Enlightenment about Translation Teaching Based on the Elements of Translation Ability and Its Developmental Stages
}

\author{
Yanwei Yang ${ }^{1}$ \\ ${ }^{1}$ Northwestern Polytechnical University Ming De College, Xi’an, Shaanxi, 710124
}

Keywords: translation ability; development stage; translation course

\begin{abstract}
The development of technology has new requirements for the composition of translation competence. Researchers at home and abroad have conducted a series of studies on the composition and development of translation competence. Based on the theoretical research on the composing factors and development stages of translation competence, this paper studies the implications of translation course teacher' teaching concepts, curriculum setting, selection and compilation of teaching materials, teaching mode, and assessment mode of English major.
\end{abstract}

\section{Introduction}

The core problem of translation teaching is to train students' translation ability. How to make them qualified translators and improve their translation ability is the primary task of translation teaching (Tong Yahui 2010: 88). Miao Ju believes that since the improvement of students' translation ability is the core of translation teaching, the starting point of translation teaching research is the development of the translator's translation ability (2007: 47). This paper studies the composition and development stages of translation ability, finds its inspiration to translation teaching, and puts forward some suggestions on translation teaching to help students form a sustainable development of translation ability and promote the lifelong development of students' translation ability.

\section{The Constituent Factors of Translation Ability and Its Development Stages}

\subsection{The Constituent Factors of Translation Ability}

What is translation ability? What are the factors of translation ability? So far, scholars in the field of translation studies have not formed a unified understanding about it, and there is even no effective model of translation ability through empirical tests (Tong Yahui 2010: 88). For a long time, scholars believe that translation ability is the ability to convert one language into another, and translation is the process which occurs between languages and cultures. Catford thinks that translation is the process of the replacement of textual material in one language by equivalent textual material in another language (1965: 20). Newmark believes that translation is to reproduce the original author's message in the text in another language (1988: 5). Shuttleworth \& Cowie believes that translation is not just a process of bilingualism but a process that takes place between two cultures (1997: 35). Before the 1970s, research on translation competence was often limited to the study of bilingual competence, cultural competence, and strategic competence. Beeby started from the goal of translation teaching and studied the composition of translation competence, including language comparison, language conversion, discourse comparison, and non-linguistic competence (Wang Shuxuan Wang Ruowei 2008: 81). PACTE's revised translation model includes five sub-competences and one element: bilingual sub-competence, extra-linguistic competence, translation expertise sub-competence, instrument sub-competence and strategic sub-competence, and the psycho-physiological element (Tong Yahui 2010: 90). Miao Ju believes that translation ability is mainly composed of cognitive ability, language ability, and communicative competence, and cognitive ability determines whether a person can become a qualified translator (2007: 48). Lian Shu-neng believes that the translator's competences include bilingual competence, cultural 
competence, writing competence, knowledge about translation theories and translation skills, and information technology competence (2012: 8-12).

Although the perspectives and levels of research on the composition of translation competences are different, it is not difficult to find that there are common elements in the constituent elements translation competence: language ability, cultural ability, instrument ability, translation expertise, strategic competence, etc. Language ability or bilingual competence includes phonetics, vocabulary, grammar, sentence pattern, discourse, expression, and writing abilities. Cultural ability includes cultural knowledge, encyclopedic knowledge, subject knowledge, cultural cognition and comparison, etc. Instrument competence refers to the ability to solve problems in the translation process by using traditional dictionaries, web dictionaries, encyclopedias, grammar books, and network resources. Translation expertise includes the knowledge of translation theory, skills, processes, units, project organization, management, and other related knowledge in the translation and translation industry. Strategic competence is the knowledge used to solve the problems that arise in the translation process, including the selection of translation skills, the use of translation strategies. The psychological factor, which has a great influence on the translation process, includes cognition, attitude and psychological mechanism, including logic analysis, thinking ability, and coordination ability

Based on the research and analysis of the above theories, we find that the main composing factors of translation competence at the present include bilingual sub-competence, cultural sub-competence, tool sub-competence, translation professional knowledge sub-competence, and psychological factor. Bilingual sub-competence is the foundation of other translation abilities, and therefore enhancing students' language ability is the key in translation course teaching. Cultural sub-competence is based on bilingual sub-competence and it play an important role in information transmission. The psychological factor is crucial to the translation ability, and determine translator's coordination ability, strategic ability, cognitive ability, etc. The strategic ability and cultural ability influence translator's language style, and affect the readability of the translation. Instrument sub-competence and translation expertise can be acquired after a short training process. The ability of translation tools is conducive to the consistency of terminology used by many people in collaboration. It can help translators save translation time and help translators to complete translation tasks quickly and accurately. It also makes it possible for international translators to complete one or more translation projects at the same time.

\subsection{The Development Stages of Translation Ability}

From the perspective of language level, Toury divides the process of translation competence into three stages: beginner, experienced translator, and expert translator. At the beginner level, translators' bilingual transformation mainly occurs in the micro-language level such as vocabulary and sentence patterns; during the experienced translator stage, bilingual transformation takes place in the more macroscopic language level such as discourse; expert translators stage, the micro and macro language conversion occurs flexibly and naturally with the frequent application of translation strategies to solving the problem of cultural dimensions (Wang Shuyu Wang Ruowei 2008: 83). Shreve thinks that the development of translation competence has the following characteristics: 1) As with any learning process, the development of translation competence is dynamic and spiraling. 2) In translation competence development, the development of operational knowledge and translation strategy capabilities is the most fundamental. 3) In translation competence development, all the sub-competences have been developed and reorganized (Ma Huijuan 2012: 105). PACTE research group found that the acquisition of translation competences is a dynamic, spiral process through research on translators' acquisition of translation abilities. Similarly, PACTE research group believes that translation competence development is a process that moves from "introductory knowledge" to "professional knowledge." (Tong Yahui 2010: 88). Chesterman divided translation ability development into five phases: beginner, advanced phase, competence phase, proficiency phase, and expert level (2000:77). The theoretical research on the development stages of translation competence found that translation competence development has a dynamic upward trend. The 
development of various sub-abilities in the process of translation and the pace of progress vary from person to person but those sub-competences can be cultivated through targeted translation teaching and individual training interventions. The constituent elements and development stages of translation competence have found a breakthrough for the development of English majors' translation competence.

\section{Development of Translation Courses of English Majors Based on Translation Competence Development}

\subsection{Teacher's Teaching Concept}

Teachers should be aware that translation ability is both static and dynamic. At a particular moment translation ability is a kind of static ability and its law can be studied to serve for translation teaching. It is dynamically developed and can be improved by certain means. When teachers find students' problems in translation teaching, they can give them guidance or carry out targeted translation training for them. In teaching teachers should not only pay attention to the majority of students but also focus on the individual differences of students in order to make students develop together. In addition, teachers need to pay attention to the cultivation of student's language ability, making them know the differences between the two languages and cultures so as to make student's translation achieve the effect of the original text. Teachers should cultivate students' judgment ability of language quality and the appreciation of translation to make students have the ability evaluate translations based on certain translation theories. Teachers should pay attention to improving students' cultural awareness, promoting mutual understanding and acceptance among cultures, and promoting good intercultural communication. Teachers should help students with the cultivation of students' responsibility, confidence, and teamwork.

\subsection{Curriculum Setting}

The curriculum setting should focus the development of language foundation and other sub-abilities, and pay attention to the interrelationship between various sub-abilities. Bilingual ability is the basis. Without good language skills, there is no way to discuss other translation competences. In the setting of English majors' courses of lower grades, the amount of language classes should be increased and the language foundation of students should be strengthened so as to prepare them for the natural bilingual transformation. In the upper grades, cultural courses such as: Anglo-American Society and Culture, Chinese Society and Culture (in English), Encyclopedic Knowledge Courses, etc. should be set up to improve students' cultural awareness, cultural contrast and communication competences; and computer-aided translation courses should be offered to them so that they'll have the ability to use translation software, modern translation tools, network resources, corpus search and screening, etc.; translation theory and practice, appreciation courses should be set up in order to improve students' translation skills and strategies and enhance students' ability to evaluate texts and translations; holidays Interpreting practical practice also needs to be opened so that students will have the opportunity to combine the theory and practice in the authentic situation.

\subsection{Selection and Compilation of Teaching Materials}

The teaching material can't be relied on one textbook and teachers need to integrate multiple translation books as the teaching material. According to the specific circumstances of their students, teachers can form a translation ability model which allows students to fully grasp translation theories and methods and improve their ability to translate languages. Various institutions of higher learning can also compile suitable translation teaching materials according to their characteristics and professional features. The compilation of teaching materials should keep up with the pace of the times and meet the characteristics and tastes of modern young people. The textbooks should have translations of domestic and foreign news to broaden students' horizons, cultivate students' patriotism and international perspectives, stimulate their interest and initiative in 
learning translation, and lay a language foundation for the future pattern of life. Compiled textbooks should also deal with basic translation research issues such as translation concepts, standards, methods, and strategies. They should contain relevant translation theories like functional equivalence, teleology, eco-translation theory, and other modern theories. The selected texts should be divided into subjects, including literature, education, sports, politics, and entertainment, technology texts, ect. to improve students' translation ability from different levels and fields.

\subsection{Teaching Mode}

Translation ability is a comprehensive ability of language, culture, communication, tools, and professional sub-abilities in the process of language processing, which can be cultivated and is dynamically rising. The accumulation of English and Chinese and the natural transformation of English and Chinese are the basis for the development of translation ability. The traditional teaching model of translation courses is teacher-centered and focuses on the transmission of knowledge. However, there are too little supervision on student's internalization process of knowledge and it is difficult to pay attention to individual differences among students. There are few concerns about the development of students' translation process, so it is difficult to achieve translation expectation of students' translation competence development. Miao Ju proposed that the Process-based Teaching Method should be adopted in translation teaching, and students should undergo the translation process through the discussion mode, so that students can comprehensively obtain the translation ability in practice (2007:50). In translation teaching, the traditional translation teaching model and the flipping classroom model should be combined to make up for the inadequacies of traditional teaching (Pang Bingchao 2015: 88).

\subsection{Assessment Mode}

With the advancement of modern science and technology and the concept of teaching research, the translation classroom teaching mode has changed: the translation classroom activities and homework forms are diverse, and the evaluation system of students' translation ability is also constantly improving. The traditional summative assessment mode can only reflect the result of an examination or the student's ability to translate materials of a particular subject. It does not adequately manage the students' translation process and is not conducive to the formation of students' good learning habits. Only emphasizing language ability and ignoring the development of other sub-abilities cannot meet the requirements of modern society for students. This series of changes has brought new directions to the evaluation system of translation courses. Teachers can adopt formative assessment system to evaluate the development of students' translation ability. Parameter setting and score ratio of translation course formative assessment system can be complicated but effective. All kinds of classroom activities, students' cooperation, and assignments should all take up a certain score, and students' internal driving forces such as learning attitude, enthusiasm, responsibility, and curiosity can all be set as assessment parameters.

\section{Conclusion}

Language sub-competence is the basis of translation ability. Without language ability, there is no translation ability. How to effectively promote the bilingual sub-competence and promote the natural transformation between languages is a subject that teachers need to study. The composition and development stages of translation competence also find the starting point for the study of curriculum setting, curriculum syllabus, teaching mode, assessment method, selection and compilation of teaching materials, etc. In translation teaching, teachers should improve their own concepts, set up reasonable courses, choose suitable modern translation texts, use divers teaching methods, and construct a reasonable assessment system, paying attention to the cultivation of students' internal driving force and help students to improve their comprehensive translation competence. 


\section{References}

[1] Catford, J. C. A Linguistic Theory of Translation: An Essay in Applied Linguistics. Oxford: Oxford University Press, 1965.

[2] Chesterman, Andrew. Teaching Strategies for Emancipatory Translation. In Christina Schäffner \& B. Adab, 2000: 77-89.

[3] Newmark, Peter. Approaches to Translation. Oxford: Pergamon Press, 1988.

[4] PACTE. Building a Translation Competence Model. F. Alves. Triangulating Translation: Perspectives in Process Oriented Research. Amsterdam/ Philadelphia: John Benjamins, 2003: 43-66.

[5] Shreve, Gregory M. Cognition and the Evaluation of Translation Competence. In Joseph H. Danks, Gregory M. Shreve, Stephen B. Fountain and Michael K. McBeath (eds). Cognitive Processes in Translation and Interpreting. Thousand Oaks: Sage Publications, 1997: 120-136.

[6] Shuttleworth, M. \& M. Cowie. Dictionary of Translation Studies. Manchester: St. Jerome Publishing, 1997, 35.

[7] Lian Shuneng. English-Chinese Translation Course. Higher Education Press, 2012:8-12.

[8] Ma Huijuan. A Study on Chinese Learners' Translation Ability in C-E Translation. Foreign Language Teaching, 2012(1): 105-108.

[9] Miao Ju. Translation Ability Research - The Foundation of Translation Teaching Mode. Foreign Languages and Their Teaching, 2007 (4): 47-50.

[10] Pan Bingchao. Experimental Study on the Application of Overturned Classroom Mode in College Teaching. Curriculum and Teaching, 2015 (3): 83-88.

[11] Tong Yahui. Research on PACTE Translation Competence Mode. Journal of PLA University of Foreign Languages, 2010 (5): 88-93.

[12] Wang Shuyu, Wang Ruowei. Research on the Components and Development Level of Translation Ability. Foreign Language Research, 2008 (5): 80-88. 